\title{
Natural Intelligence and Anthropic Reasoning
}

\section{Predrag Slijepcevic ${ }^{1}$}

Received: 18 January 2020 / Accepted: 2 July 2020/Published online: 13 July 2020

(C) The Author(s) 2020

\begin{abstract}
This paper aims to justify the concept of natural intelligence in the biosemiotic context. I will argue that the process of life is (i) a cognitive/semiotic process and (ii) that organisms, from bacteria to animals, are cognitive or semiotic agents. To justify these arguments, the neural-type intelligence represented by the form of reasoning known as anthropic reasoning will be compared and contrasted with types of intelligence explicated by four disciplines of biology - relational biology, evolutionary epistemology, biosemiotics and the systems view of life - not biased towards neural intelligence. The comparison will be achieved by asking questions related to the process of observation and the notion of true observers. To answer the questions I will rely on a range of established concepts including SETI (search for extraterrestrial intelligence), Fermi's paradox, bacterial cognition, versions of the panspermia theory, as well as some newly introduced concepts including biocivilisations, cognitive/semiotic universes, and the cognitive/semiotic multiverse. The key point emerging from the answers is that the process of cognition/semiosis - the essence of natural intelligence - is a biological universal.
\end{abstract}

Keywords Natural intelligence $\cdot$ SETI $\cdot$ Anthropic reasoning $\cdot$ Biosemiotics $\cdot$ Bacterial cognition $\cdot$ Fermi's paradox $\cdot$ Biocivilisations

\section{Introduction}

The purpose of this study is to justify the concept of natural intelligence - the type of intelligence wider than human intelligence and its derivative AI (Kurzweil 1990; Vinge 1993; Bostrom 2014; Price 2016) - in the biosemiotic context. Thus, the term 'intelligence' will be used as an equivalent to 'semiosis' in biosemiotics, and the term 'cognitive agent' will be used equivalently to 'semiotic agent'. The study will compare

Predrag Slijepcevic

predrag.slijepcevic@brunel.ac.uk

1 Department of Life Sciences, College of Health and Life Sciences, Brunel University London, Uxbridge UB8 3PH, UK 
arguments from four disciplines of biology not biased towards neural intelligence relational biology, evolutionary epistemology, biosemiotics and the systems view of life - with arguments that are rooted in and biased towards the neural-type intelligence, such as those used in the Anthropic Principle (AP) reasoning or anthropic reasoning (Carter 1974; Barrow and Tipler 1996).

According to AP, the universe appears to be fine-tuned for intelligent life and the emergence of observers - if cosmological constants are not exactly as they are, there would be no observers. The AP debate centers around two arguments: (i) the universe is intentionally created for us as intelligent observers and (ii) intelligent life is the result of improbable events that would not be replicated in other universes. The first option is consistent with the existence of an external "creator", either God (an option that is discarded as unscientific), or the possibility that life on Earth is seeded from other cosmic locations as argued by the proponents of the directed panspermia hypothesis (Crick and Orgel, 1973). The second option implies the existence of many universes (multiverse), one (or only a few) of which (including our universe) contains life (Tegmark 2009). However, there is another option that may be called the life principle (Davies 2003). Given the abundance of the molecular material for life and the ubiquity of stable stars and habitable planets, the emergence of life is a 'cosmic imperative' (de Duve 2011). The life principle is consistent with the concepts of biocentrism (Lanza and Berman 2009), biological determinism (Davies 2003; De Duve 2011) and some forms of the panspermia hypothesis, such as the Hoyle-Wickramasinghe $(\mathrm{H}-\mathrm{W})$ thesis (e.g. Hoyle and Wickramasinghe 1981) and transpermia (Davies 2003). In this study I will use anthropic reasoning to arrive at the position, broadly consistent with life principle, but also with biosemiotics, that natural intelligence is a biological universal - organisms from bacteria to animals are cognitive or semiotic agents - and that the human-type intelligence is only a fraction in the wide spectrum of natural intelligence which may be equivalent to semiotic scaffolding: "a tightly wound web of checks and balances gradually establishing itself through myriads of semiotic interactions between organisms" (Hoffmeyer 2015, p 154).

Here is a sketch of anthropic reasoning as derived from Bostrom (2002). The process of sampling the world by which we, as observers, interact with the world is limited by the inability of our observational faculties to capture the totality of information about the world. The consequence of these relationships between observers and the world are observation selection effects - we are necessarily handicapped as observers (Maor et al. 2008). This handicap is frequently dubbed anthropic bias. The function of anthropic reasoning, on the other hand, is to attempt to eliminate various forms of anthropic biases. This can be achieved by pushing the borders of human understanding of the world to its limits, by combining the cutting-edge scientific evidence with the type of argumentation necessary to avoid pitfalls of the sampling bias.

I start by giving a brief overview of AP and associated concepts from the perspective of biology. I then focus on the concept of observation as understood by AP on one side, and relational biology, evolutionary epistemology, biosemiotics and the systems view of life on the other. This comparison uncovers fundamental differences between the two sides and paves the way for applying anthropic reasoning further through asking questions aimed at understanding the process of observation and true observers. I 
conclude with the analysis of AP from the new angle which is not biased towards the neural-type intelligence.

\section{A Brief Overview of AP and Associated Concepts}

The AP concept was developed by astrophysicists and philosophers as an analogy to the Copernican or mediocrity principle, which states that humans are not expected to occupy a privileged position in the universe (Carter 1974). By contrast, AP is consistent with the notion that the position of Homo sapiens is to some extent privileged: we are a species capable of (i) cognition, which includes observation at the scale of the universe (observable universe) and (ii) interpretation of our position in the universe. AP is thus an argument against the Copernican principle. Given that biology is neutral about the position of individual species relative to the rest of nature, AP is criticized by some biologists (e.g. Barash, 2018). However, this does not mean that AP is without any value to biology. Here is a sketch of AP adapted to biology.

Our sensorium registers only a subset of signals/stimuli available in the external world, leading to observation selection effects. For example, we tend to view animals and people as independent individuals, even though they are composed of numerous parts that once possessed individuality. As a result, artists typically depict people as absolute individuals. Lisa Gherardini, used by Leonardo da Vinci (1452-1519) as a model for the Mona Lisa, exists in the mind of the artist, and the minds of the observers of Mona Lisa, as an undisputed individual. By contrast, a counterintuitive artistic vision of Giuseppe Arcimboldo (1527-1593) depicts individuals as composites (Slijepcevic 2019b) (Fig. 1). Unlike Mona Lisa, a rigid biological singleton, Flora is a composite organism formed by the merger of formerly independent organisms (Fig. 1).
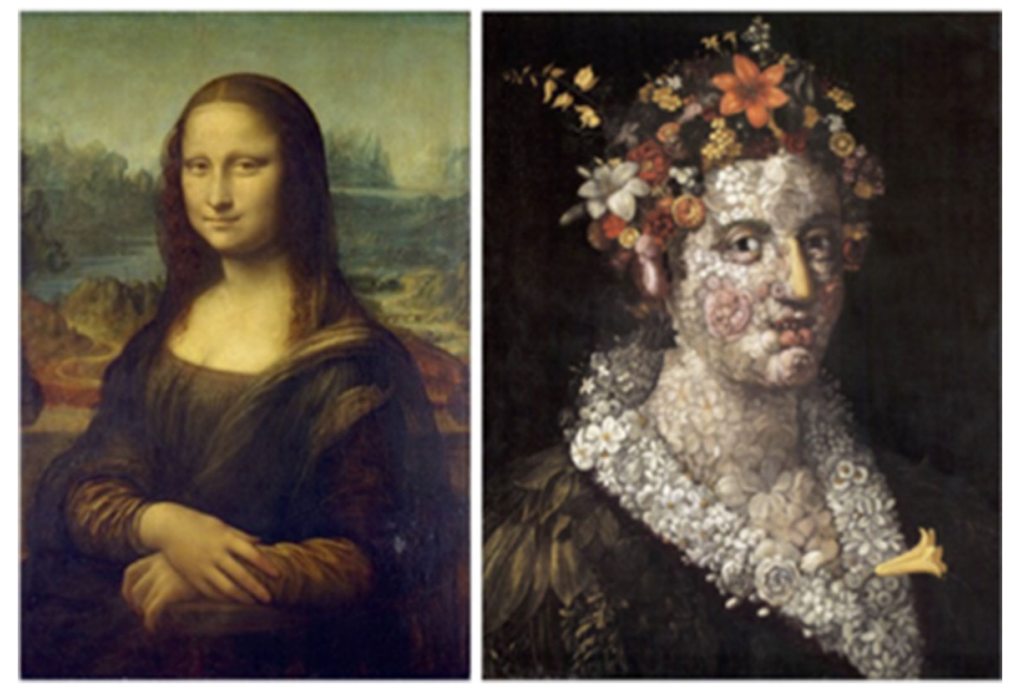

Fig. 1 Mona Lisa (c.1503-1506) by Leonardo da Vinci and Flora (1588) by Giuseppe Arcimboldo. Images courtesy of Wikimedia Commons (https://commons.wikimedia.org/wiki/Category:Mona_Lisa \& https://commons.wikimedia.org/wiki/File:Giuseppe_Arcimboldo_-_Flora_-_WGA0834.jpg) 
From the perspective of modern biology, Flora may be considered a more authentic portrait than the Mona Lisa. Human bodies are complex ecological collectives consisting of 37 trillion human cells (themselves collectives formed by the microbial mergers) and 400 trillion microbes which together form symbiotic partnerships known as holobionts (Margulis 1993; Zilber-Rosenberg and Rosenberg 2008). Apart from the most basic microbes, bacteria and archaea, which are the only true biological singletons, all other organisms - protists, fungi, plants, and animals - are archaeal-bacterial mergers and thus composites. Absolute individuals do not exist above the level of single-cell prokaryotic microbes. On this understanding, life is an organic conglomerate of transient composite forms. By the same token, evolution is the process of the change of the composites.

Observation selection effects in this case (Fig. 1), represent the difference between the intuitive artistic vision of Leonardo da Vinci formed based on insufficient evidence about the true structure of human bodies, and the counter-intuitive artistic vision of Arcimboldo, which, though metaphoric, is in some ways more accurate because the unusual artistic imagination happens to be in line with modern scientific evidence.

Thus, observation selection effects are the consequence of a specific epistemic position of the human observer relative to the world. This interplay between our capacity to observe the world and the evidence we use to justify the accuracy of our observations is called anthropic reasoning (Bostrom 2002). This type of reasoning stems from the AP concept (Carter 1974), which implies that our position in the universe is privileged to some extent "in so much as special conditions are necessary for our very existence" (Carter 1983). Carter (1974) articulated two forms of AP, known as weak AP (WAP) and strong AP (SAP). WAP states that our position in the universe is privileged because our existence is dominated by our capacity to observe the surrounding world and the universe at large. On the other hand, SAP includes an imperative that the universe must allow the emergence of observers at some stage in its development. Barrow and Tipler (1986) formulated their versions of WAP and SAP, which deviate from Carter's by allowing a greater degree of teleology. They also formulated a final AP (FAP), which states that an information processing capacity must emerge in the universe and once it emerges it will never die out. Finally, Wheeler (1994) argued for Participatory Anthropic Principle (PAP) according to which observers are necessary to bring the universe into existence.

In spite of differences between various forms of AP, they share a common feature. All forms of AP assume that the minimum requirement for the true observing capacity is the human-type intelligence (neural intelligence), which eventually peaks in science and technology. Thus, AP holds that the observers must possess, at the minimum, the human-type intelligence plus techno-science, or techno-science-like method, as a form of knowledge acquisition. If we accept this assumption, three types of observers are possible in the universe (i) humanity bound to Earth (and on the verge of the cosmic adventure) possessing techno-science at the present state of development as a form of knowledge acquisition, (ii) humanity-like civilisations living somewhere else in the universe, and (iii) civilisations with the observing capacities superior to the capacities of human or human-like civilisations, living somewhere else in the universe. From this, it also follows that AP assumes two distinct territories of life, as we know it on the planet Earth: (i) intelligent life represented by Homo sapiens and its technology in the form of techno-science and (ii) all other forms of life (microorganisms, plants, and 
animals) considered either non-intelligent or not intelligent enough from the perspective of observing capacities. This position is apparent, for example, in Drake's equation (Drake 1961) devised to estimate the number of extraterrestrial civilisations in the Milky Way galaxy.

$N=R * f_{\mathrm{p}} n_{\mathrm{e}} f_{1} f_{\mathrm{i}} f_{\mathrm{c}} L$.

where:

$N=$ the number of civilisations in our galaxy with which we can communicate.

$R^{*}=$ average rate of star formation in our galaxy.

$f_{\mathrm{p}}=$ fraction of stars with surrounding planets.

$n_{e}=$ number of planets that can support life.

$f_{1}=$ fraction of planets from the $n_{\mathrm{e}}$ pool that develop life.

$f_{\mathrm{i}}=$ fraction of planets with life that develop intelligent life.

$f_{\mathrm{c}}=$ fraction of civilisations that develop technology for emitting signals in space.

$L=$ the length of time during which signals are emitted.

Three components in the equation $-f_{1}, f_{\mathrm{i}}$, and $f_{\mathrm{c}}$ - deal with the distinction between the life-developing and intelligence- or technology-developing potentialities of civilisations.

However, I will argue that the key AP assumption is wrong. I define the key AP assumption as follows:

The human-type intelligence (neural intelligence) and humanity-type civilisation supported by techno-science, is the minimal type intelligence/civilisation capable of the true observation at the cosmic scale.

I will also argue that there are no fundamental differences between the observing capacities of, for example, bacteria and Homo sapiens (Shapiro 2007; Ben-Jacob 2009; Lyon 2015, 2017). Intelligence emerges not only in the case of interacting neural cells but also in the case of interacting bacteria that turn their colonies into brain-like entities (Ben-Jacob 2009; Slijepcevic 2018). My argument is rooted in the notion that the process of life is inherently an observation-like process whereby all organisms are cognitive or semiotic agents and the process of evolution is a cognitive process (Maturana and Varela 1980), or semiotic scaffolding (Hoffmeyer 2015). This view is consistent with different versions of life principle including biological determinism (Davies 2003), biocentrism (Lanza and Berman 2009), cosmic imperative (De Duve 2011) and different forms of the panspermia hypothesis (Hoyle and Wickramasinghe 1981; Davies 2003). In particular, the notion of organisms as cognitive agents capable of sensing and processing environmental stimuli or biological information (Slijepcevic 2019a) is consistent with the informational view of life implicit in the concept of biological determinism (Davies 2003), or the concept of semiotic scaffolding (Hoffmeyer 2015).

\section{Arguing against the Key AP Assumption}

The motivation behind developing an argument against the key AP assumption is in line with anthropic reasoning - the purpose of anthropic reasoning is to reduce anthropic bias. For the sake of argument, let us assume that Fermi's paradox maybe a source of anthropic bias. Fermi's paradox may be stated as follows. The expectation is, in line with the astrophysical arguments based on the size and age of our galaxy, that 
humanity-type civilisations, with developed technologies for cosmic communication and travel, should exist and yet there is no contact with them in spite of SETI efforts (Jones 1985). We can argue further, based on the above assumption, along the following lines. Given that several decades have passed since the establishment of the SETI programme, at the heart of which is the AP assumption, and yet not a single piece of evidence was obtained to support SETI, an alternative hypothesis must be considered. The aim of the alternative hypothesis is to advance anthropic reasoning through reducing the anthropic bias by being more inclusive of the new evidence from biology.

To advance the case against the AP assumption I will proceed as follows. The AP assumption can be shortened into the following statement: There are no true observers in the universe below the human-type observers. The first task in developing the counter-argument is to define (i) the process of observation and (ii) the notion of true observers. To achieve this we can rely on Brandon Carter's recognition that the term "cognition principle" (Carter 1983) may have been less problematic than the somewhat inappropriate term AP.

Therefore, substituting the word anthropic with the word cognition (AP becomes $\mathrm{CP}$ ) provides a shortcut towards defining the concepts of observation and true observers. The process of observation may be interpreted as a cognitive process. It consists of three components: the knowing subject (humanity), the object to be known (the world or the universe) and the pool of knowledge used to justify our position in the world (technoscience at the present state of human development; mythologies, religions, and pre-science philosophy in the past) (Fleck 1981). From the perspective of AP, humanity self-selects evidence from the existing pool of knowledge, best suited to describe our position in the world/ universe, in line with the prevailing collective opinion. The AP position is consistent with the view that the cognitive capacity, as described above, exist only in one species on Earth, Homo sapiens.

This leads us to consideration of the concept of true observers. The SETI programme implies that true observers must be human-like observers: those observers that can (i) perceive local and cosmic-level information through natural sensorium and man-made technologies, or equivalents, (ii) reflect on the sensory inputs with the help of the accumulated explanatory apparatus (a techno-science like method), and (iii) direct its reaction on the cosmic scale through, for example, emitting and detecting signals in space using appropriate technologies with the hope of establishing contacts with similar non-local civilisations that share temporal and spatial coordinates within the range of the signal (Ćirković and Vukotić 2013). Again, the AP position is clear. Only one species (or reference class of observers) on Earth has this capacity, Homo sapiens.

To start developing the counter-argument one can ask questions aimed at probing the applicability of the observation process and the concept of true observers on reference classes other than Homo sapiens. Here is the list of four such questions.

- Are human observers the only observers within the pool of terrestrial life forms? (Q1).

- If not, (a) what's the frequency of non-human observers within the pool of terrestrial life forms (some life forms, or all life forms); and (b) if all life forms are observers, what's the boundary between the observing and non-observing capacities? (Q2). 
- Are there true observers within the pool of terrestrial life forms amongst the reference classes of observers that are not human? (Q3).

- Do human observers and other observers and true observers share common features? (Q4).

To formulate answers to Q1-4 I need to outline positions of the four disciplines of biology, relational biology, evolutionary epistemology, biosemiotics and the systems view of life, about how they interpret the process of cognition. A feature these four disciplines of biology share is the independence from the neural-type intelligence when it comes to interpreting cognition (see below). Only when the positions of these four disciplines of biology are stated, I can proceed with answering Q1-4.

\section{The Concept of Cognition from the Perspective of Four Disciplines of Biology}

What follows is a summary of theoretical bases for each discipline of biology. For a more detailed exposition of each topic, readers are referred to the essential set of references used in the text.

\section{Biosemiotics}

The concept of semiosis, or sign utilization, involved two opposing schools. A linguist Ferdinand de Saussure (1916) used the term semiology to study signs within the subject of psychology. In his interpretation, the sign was a dual entity consisting of a signifier and a signified. On the other hand, Charles Saunders Peirce (1906), invented the triadic concept of sign consisting of a sign vehicle, an object, and an interpretant. This triadic concept is accepted by modern biosemiotics. However, the process of turning the concept of semiosis into a fully-fledged scientific discipline of modern biosemiotics, included several steps (Barbieri 2009).

The discovery of the genetic code pointed to the existence of "[a] language much older than hieroglyphics, a language as old as life itself ... its letters are invisible and its words are buried in the cells of our bodies" (Beadle and Beadle 1966). As soon as it was discovered, the genetic code was interpreted as a form of language used by the cell, which in turn becomes a semiotic system. In this semiotic system, signs or symbols are required for various cellular functions. Pattee (1968) articulated the idea that the cell is controlled by the symbols. By incorporating a range of ideas into semiosis including molecular biology, the genetic code, and Von Neuman self-replicating automata, Pattee argued that "life is matter controlled by symbols" (Pattee 2008).

This paved the way for the emergence of zoosemiotics, the proposal that animal communication is based on signs (Sebeok 1972). The reasoning behind zoosemiotics was based on the writings of Jakob von Uexküll. This almost forgotten biologist provided a large body of evidence for the existence of semiosis in the world of animals (Uexküll 2010). Additionally, Thomas Seboek, with the help of collaborators including Prodi (1988) and Krampen (1981), and relying on the evidence generated by other scientists (Sonea and Panisset 1983; Sonea 1987, 1988), articulated the view that a primitive form of semiosis or protosemiosis exists in the world of microorganisms and plants. All this enabled the birth of modern biosemiotics based on two key principles 
(Barbieri 2009). First, "life and semiosis are coextensive". Biosemiotics is what makes animate matter different from the inanimate equivalent. Second, the existence of signs, meaning, and codes separates biosemiotics from "intelligent design" and doctrines, which assume that the origin of life has supernatural roots.

The consequence of biosemiotics is the emergence of the concepts of "semiotic scaffolding" and the semiosphere. Jesper Hoffmeyer (2015) defined semiotic scaffolding as the network of semiotic interactions that permeates the entire nature: the web of sensing, interpreting and coordinating social interactions between organisms of the same species and organisms of different species, through various forms of crosskingdom communication. The semiosphere, on the other hand, is "[a] sphere like the atmosphere, hydro-sphere, or biosphere. It permeates these spheres from their innermost to outermost reaches and consists of communication: sound, scent, movement, colors, forms, electrical fields, various waves, chemical signals, touch, and so forth —in short, the signs of life" (Hoffmeyer 1996, vi).

\section{Relational Biology}

The most prominent proponent of the school of relational biology, originally established by a physicist Nicolas Rashevsky, was his Ph.D. student, Robert Rosen (Louie and Kercel 2007; Louie 2010). To explain how science works, Rosen developed the concept of a modelling relationship between the natural system (NS) and the formal system (FS) (Fig. 2 A).

From the perspective of the human understanding of it, the world is divided into the self (individual and collective humanity) and its ambience (the rest of the world) (Rosen 1991). The structure of the world is such that there is a congruence between the self and its ambience. For example, the self (NS) internalizes the ambience through its model of it (FS), based on language and mathematics. The key thing in the modelling relationship is the concept of information which in Rosen's diagram (Fig. 2 A) is represented by arrows indicating encoding and decoding. Rosen used the mathematical category theory to map the relationship between NS and FS. In this form of mapping, encoding represents measurements or abstractions. All measurements are generated through our senses or technological extensions of our senses (scientific instruments). Thus, the abstraction becomes a form of internalization of the ambience

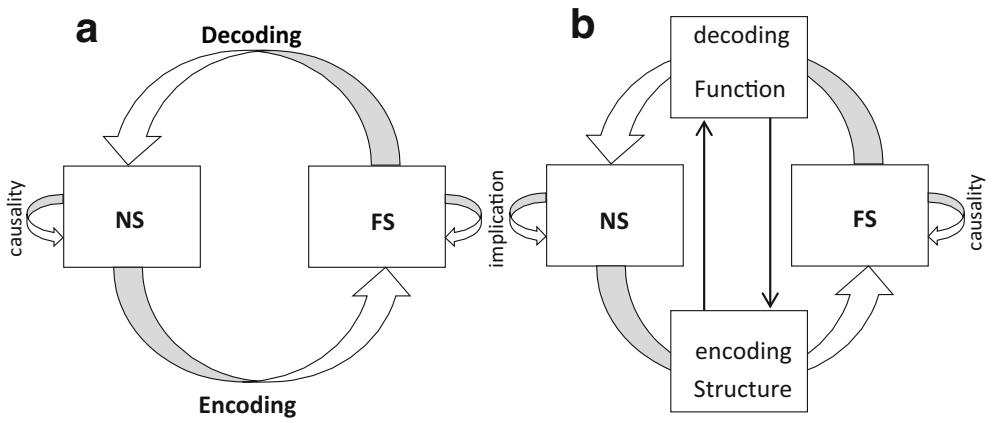

Fig. 2 A. The modelling relationship between the natural system (NS) and the formal system (FS) according to Rosen (1991). B. Inclusion of structure and function in the modelling relationship (Kineman et al. 2007). Illustrations adapted from Rosen (1991) and Kineman et al. (2007) 
by the self through the scientific analysis of entities in the observable world. Decoding, on the other hand, represents an "operator" that makes changes either in NS or FS to test the modelling relationship. Rosen's category-theoretic mapping revealed that there is commutativity between the properties of NS such as causality, and the mathematical properties of FS including entailment (implications of the model, Fig. 2 A).

At the heart of Rosen's model is an attempt to explain the epistemological relationship between any natural entity (NS) and knowledge of it (FS) (Fig. 2 A). Rosen postulated that the entire nature models itself and it is casually entailed in the form of a modelling relationship presented in Fig. 2 A. In other words, science is humanity's way of modelling nature. Similarly to humans, all other species use species-specific epistemological methods to produce modelling relationships.

To explain the universality of Rosen's model Kineman $(2007,2011)$ and Kineman et al. (2007) introduced biological structure and function into the model (Fig. 2 B). The structure and function are the emergent properties of the modelling relationship resulting from the original Rosen's diagram (Fig. 2 B). The structure is represented by natural measurements or abstractions executed by the sensorium of each species. The "operator" behind the process of decoding in the original diagram (Fig. 2 B), when applied to the entire natural world, becomes the process of the epistemological search for the biological function. The entire process is tested by the filter of natural selection the filter tests various structure-function forms that emerge from the process of biological abstraction leading to functions such as vision, flight, natural computation, etc. Thus, the empirical world is emerging from the epistemological-ontological unity implicit in Rosen's model. The consequence is that all biological systems, from bacteria to ecosystems, are anticipatory systems that contain internal predictive models of themselves and their environments (Rosen 1985).

\section{Evolutionary Epistemology}

The programme of research in evolutionary epistemology (Bradie 1986; Plotkin 1987; Gontier 2006) was initiated by Campbell $(1960,1974)$. The key assumption behind the branch of evolutionary epistemology known as EEM (evolutionary epistemology mechanisms) was that animals are true learners or "knowers" (Plotkin 1982). The original position of EEM was recently revised to take account of the cognitive abilities of all forms of life including prokaryotic microorganisms (bacteria and archaea), eukaryotic microorganisms (protists), fungi (single- and multi-cellular), plants and animals (Slijepcevic 2018, 2019a). This more recent version of EEM reflects better the original principles formulated by Plotkin (1982): (i) living systems are knowledge systems, (ii) evolution is the process of gaining knowledge and (iii) there are features shared by all forms of knowledge gain.

In brief, all organisms, from bacteria to animals, acquire knowledge about their environments through the process of natural learning based on a universal algorithm. The driving force behind the algorithm is the concept of biological information. In the context of biology, information is a purely relational concept. Any form of information becomes actualized only when there is a cognitive system capable of utilizing it. Information, when non-utilized by a cognitive system, exists only as potential information $\left(\mathrm{I}_{\mathrm{p}}\right.$ ) (Jablonka 2002; Corning 2007). For example, the presence of sugar molecules in a watery solution lacking cognitive systems such as bacteria may be 
interpreted as a passive form of information or $\mathrm{I}_{\mathrm{p}}$ (Slijepcevic 2019a). Once the bacteria become part of the watery environment containing dissolved sugar, they detect the sugar with its sensory apparatus. The passive form of information, or $\mathrm{I}_{\mathrm{p}}$, once detected by the bacterial sensory apparatus, becomes actualized and turns into control information $\left(I_{c}\right)$ (Corning 2007; Slijepcevic 2019a). This triggers the algorithm for natural learning.

However, the automated algorithm process may not be consistent with the notion of organisms as autonomous natural agents. Thus, the term algorithm should be softened and viewed as a descriptor for the sequence of events behind the cognitive process, rather than an algorithm in the truly mathematical sense. Most importantly, through the process of natural learning organisms create their environments.

\section{Systems View of Life}

The emergence of systems theory (Bertalanffy 1968), cybernetics (Wiener 1948), information theory (Shannon and Weaver 1949) and complexity theory (Mandelbrot 1983; Nicolis and Prigogine 1989) greatly influenced some of the basic concepts in biology. As a result, living systems are viewed as open thermodynamic systems, far from equilibrium, that constantly exchange matter, energy, and information with their surroundings. The key feature of living systems is not their composition, the nature of chemical constituents that make them up, or matter, but rather the pattern in which the matter is organized to produce various organismal forms (Capra and Luisi 2014). Systems theorists and cyberneticists identified a common pattern of organization that typifies all living systems - the network pattern. The entire biosphere is a giant network consisting of intertwined webs or networks nesting within the larger networks. The key property of any network is non-linearity - the pattern of organization within the network goes in all directions. As a message, or information, travels along the network pattern it may take a cyclical path leading to the establishment of a feedback loop. Indeed, the organization of living systems from cells to societies is replete with feedback loops, which eventually enable the living systems, including the biosphere at large, to self-regulate.

This system's thinking resulted in two important concepts in biology, autopoiesis and embodied cognition, developed by Maturana and Varela (1980). The key feature of the autopoiesis concept is self-organization or self-making (auto - self; poiesis - making). According to Maturana and Varela every organism, from single-cell microbes to complex multicellular animals, is an autopoietic unit - a system that sustains itself due to the network pattern of organization, which allows constant self-regeneration within the boundary that separates the autopoietic unit from its environment. However, autopoietic units are never truly separated from the environment. There is a structural coupling between the autopoietic unit and its environment.

The nature of interactions between organisms and their environments is cognitive the mind-like or brain-like (Maturana and Varela 1980). Any living organism, irrespective of whether that is a bacterium or an elephant, decides autonomously, through its sensorium faced by various constraints, whether to notice a stimulus in the environment and whether to react to it. Noticing and reacting to the stimulus leads to structural changes within the organism and within its environment. Through these 
structural changes organisms "bring forth a world", based on their own decisions which stimuli to notice and react to. As Capra and Luisi (2014) suggested: "[C]ognition, then, is not a representation of an independently existing world but rather a continual bringing forth a world through the process of living."

\section{Answering Q1-Q4}

\section{Q1}

If we (i) accept that the concept of observation is similar or equivalent to the concept of cognition (Carter 1983), (ii) acknowledge that the process of cognition involves three components (knowing subject, object to be known and some form of natural epistemology, or knowledge, as an interface between the two) (Fig. 3), and (iii) take into account evidence from the four disciplines of biology (Fig. 3), according to which the process of cognition is not limited to the neural-type intelligence, it becomes possible to argue that human observers are not the only observers within the pool of terrestrial life forms (Fig. 3). Even though the four disciplines of biology have independent research programmes they show common elements. For example, they interpret organisms as autonomous natural agents structurally coupled to their environments through speciesspecific sensoria which become tool-kits in the process of cognition (Table 1). The coupling is driven by the capacity of natural agents to read and process environmental stimuli or natural information (Table 1). This position is consistent with the informational view of life implicit in biological determinism (Davies, 2003), the increasingly cognitivist interpretation of biology (e.g. Shapiro 2007; Ben-Jacob 2009) and the principles of biosemiotics (e.g. Hoffmeyer, 2015). Therefore, the answer to Q1 is negative (Table 2).

\section{Q2}

The answer to Q2a follows logically from Fig. 3 and Table 1. Given that all organisms are natural agents with cognitive/semiotic faculties (Fig. 3; Table 1) all forms of life can be considered forms of observers (Table 2). By this logic, the first forms of life, bacteria and archaea are the most fundamental observers. All other observers are derived from them through mergers of simpler observing units into more complex ones, also known

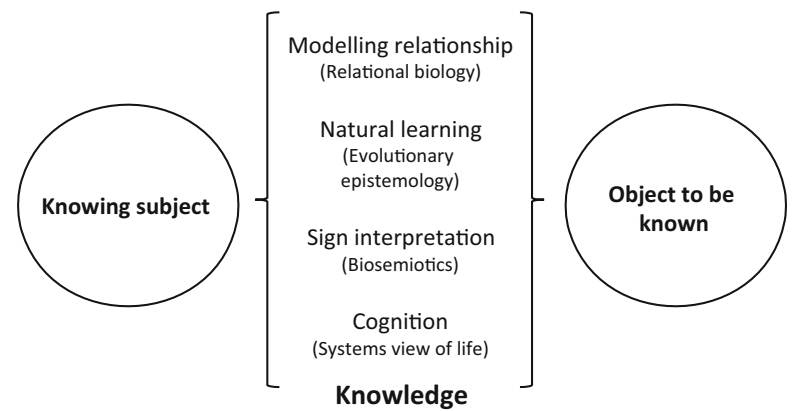

Fig. 3 The three-component process of cognition 
Table 1 Concepts of organisms, organism-environment interactions, information and information processing from the perspective of four disciplines of biology

\begin{tabular}{|c|c|c|c|c|}
\hline & $\begin{array}{l}\text { Organisms } \\
\text { as autonomous } \\
\text { natural agents }\end{array}$ & $\begin{array}{l}\text { Structural coupling } \\
\text { organism- } \\
\text { environment }\end{array}$ & $\begin{array}{l}\text { Information } \\
\text { (environmental } \\
\text { stimulus) }\end{array}$ & $\begin{array}{l}\text { Information } \\
\text { processing }\end{array}$ \\
\hline $\begin{array}{c}\text { Relational } \\
\text { biology }\end{array}$ & $\begin{array}{l}\text { Anticipatory } \\
\text { systems (Rosen } \\
1985)\end{array}$ & $\begin{array}{l}\text { Modelling relationship } \\
\text {-organisms possess } \\
\text { internal models of } \\
\text { themselves and of } \\
\text { their environments } \\
\text { (Rosen 1985, 1991; } \\
\text { see also Fig. 2) }\end{array}$ & $\begin{array}{l}\text { Structural and } \\
\text { functional } \\
\text { information } \\
\text { (Kineman 2007) }\end{array}$ & $\begin{array}{l}\text { Encoding and decoding } \\
\text { (Fig. 2). Structure = } \\
\text { model encoding; } \\
\text { function = model } \\
\text { decoding (Kineman } \\
\text { 2007) }\end{array}$ \\
\hline $\begin{array}{l}\text { Evolutionary } \\
\text { epistemology }\end{array}$ & $\begin{array}{l}\text { Cognitive agents } \\
\text { (Slijepcevic } \\
\text { 2019a) }\end{array}$ & $\begin{array}{l}\text { Natural learning } \\
\quad \text { (Plotkin 1982; } \\
\text { Slijepcevic 2019a) }\end{array}$ & $\begin{array}{l}\text { Latent information } \\
\left(\mathrm{I}_{\mathrm{p}}\right) \text { and control } \\
\text { information }\left(\mathrm{I}_{\mathrm{c}}\right) \\
\text { (Corning 2007; } \\
\text { Slijepcevic } \\
\text { 2019a) }\end{array}$ & $\begin{array}{l}\text { Natural learning } \\
\text { algorithm (Plotkin } \\
\text { 1982; Slijepcevic } \\
\text { 2019a) }\end{array}$ \\
\hline Biosemiotics & $\begin{array}{l}\text { Sign interpreters or } \\
\text { semiosis users } \\
\text { (Kilstrup 2015) }\end{array}$ & $\begin{array}{l}\text { Sign utilization } \\
\text { (Kilstrup 2015): a } \\
\text { triadic relationship } \\
\text { expressed as } \Psi(\mathrm{O}, \\
\mathrm{R}, \mathrm{I}) \text { where } \mathrm{O}= \\
\text { object, } \mathrm{R}= \\
\text { representamen, and } \\
\mathrm{I}=\text { interpretant. }\end{array}$ & $\begin{array}{l}\text { Semiotic } \\
\text { scaffolding } \\
\text { (Hoffmeyer } \\
\text { 2015) }\end{array}$ & $\begin{array}{l}\text { Sign establishment } \\
\text { phase and a sign } \\
\text { interpretation phase } \\
\text { (Kilstrup 2015) }\end{array}$ \\
\hline $\begin{array}{l}\text { Systems view } \\
\text { of life }\end{array}$ & $\begin{array}{c}\text { Autopoietic units } \\
\text { (Maturana and } \\
\text { Varela 1980) }\end{array}$ & $\begin{array}{l}\text { The process of } \\
\text { embodied cognition } \\
\text { (Capra and Luisi } \\
\text { 2014) }\end{array}$ & $\begin{array}{l}\text { "Difference that } \\
\text { makes a } \\
\text { difference" } \\
\text { (Bateson 1979) }\end{array}$ & $\begin{array}{l}\text { Autopoiesis and } \\
\text { self-organization } \\
\text { (Maturana and Varela } \\
\text { 1980) }\end{array}$ \\
\hline
\end{tabular}

as the serial endosymbiosis theory (Margulis 2004). This is visible from Fig. 1 - the human body is an ecological collective formed by the process of symbiogenesis.

A range of studies carried out in the last two decades, independently of the four disciplines of biology, confirm that the process of cognition is not confined to higher animals, but it is present in microorganisms and plants. For example, bacterial natural sensorium has been characterized as a "bacterial cognitive tool-kit" (Lyon 2015, 2017). The capacity of individual bacteria to establish communication with each other through the bacterial chemical language enables the emergence of intentionality on the part of bacterial colonies which become brain-like entities (Ben-Jacob 2009). Cognitive faculties of plants have also been documented in spite of objections from some biologists (Trewavas 2017). The biosphere may be viewed as a super-system driven and regulated by the process of cognition.

Q2b is related to defining the boundary between observing and non-observing biogenic forms. Some biogenic forms must be transitional forms - those forms that have proto-observing or proto-life capacities. Biogenic forms that lack the capacity of observation are viruses. Yet they are the most abundant biogenic forms on Earth (Moelling and Broecker 2019). Viruses cannot be characterized as autonomous agents, 
Table 2 Answers to the four questions asked in Section 3

Question

Q1: Are human observers the only observers within the pool of terrestrial life forms?

Q2a: If not, what's the frequency of non-human observers within the pool of terrestrial life forms (some life forms, or all life forms)?

Q2b: If all life forms are observers, what's the boundary between the observing and non-observing capacities?

Q3: Are there true observers within the pool of terrestrial life forms amongst the reference classes of observers that are not human?

Q4: Do human observers and other observers and true observers share common features?

\section{Answer}

Human observers are not the only observers within the pool of terrestrial life forms.

All forms of life, from bacteria to animals, are observers.

The boundary between observing and non-observing life forms are biogenic proto-observing forms such as viruses.

Yes, there are true observers within the pool of terrestrial life forms that are not human observers. These include the bacterial planetary superorganism (bacteriosphere), and the biosphere as a whole.

The common features all observers and true observers share include cognitive/semiotic universes and biocivilisations. The cognitive/semiotic universe is the collective cognitive/semiotic space of a species. The biocivilisation is the collective phenotype emerging from the cognitive/semiotic universe. The biosphere thus becomes the cognitive/semiotic multiverse, or the composite global biocivilisation.

in the same sense as bacteria. Microbiologists usually classify them as obligate parasites that require living cells for their propagation. However, the evidence is emerging that viruses have proto-cognitive faculties such as communication (Erez et al. 2017). Furthermore, viruses may be considered half-alive: proto-observers or proto-organisms, in the context of their genome size relative to bacteria and eukaryotes (Moelling and Broecker 2019).

The answer to Q2b is that the boundary between observing and non-observing capacities is represented by the proto-observing structures such as viruses (Table 2). The answer is in line with the continuity thesis - the emergence of life is an integral process of the evolution of cosmos (de Duve 2011). The key question then becomes: when did exactly proto-observers, such as viruses, emerged in the cosmic history (Fig. 4)?

The temporal scale of the cosmos is 13.8 billion years (BY). Life, as we know it, has been existing for at least 3.8 BY. The proto-observers must have emerged at any time between the point at which the process of creation of chemical elements required for biogenic structures was completed (point 1) and the point at which life emerged on Earth in the form of first fully functioning organisms or observers (point 2) (Fig. 4). The time-scale between points 1 and 2 is short in the case of the most prevalent hypothesis, that life emerges through the process of abiogenesis. For example, the cosmic imperative thesis (de Duve 2011) is based on the assumption that principles of life are inherent in the laws of physics and chemistry - abiogenesis may be widespread in the cosmos. This means that life will emerge spontaneously at an Earth-like planet. Given that the first planets were formed much earlier than Earth (Lineweaver 2001), it 


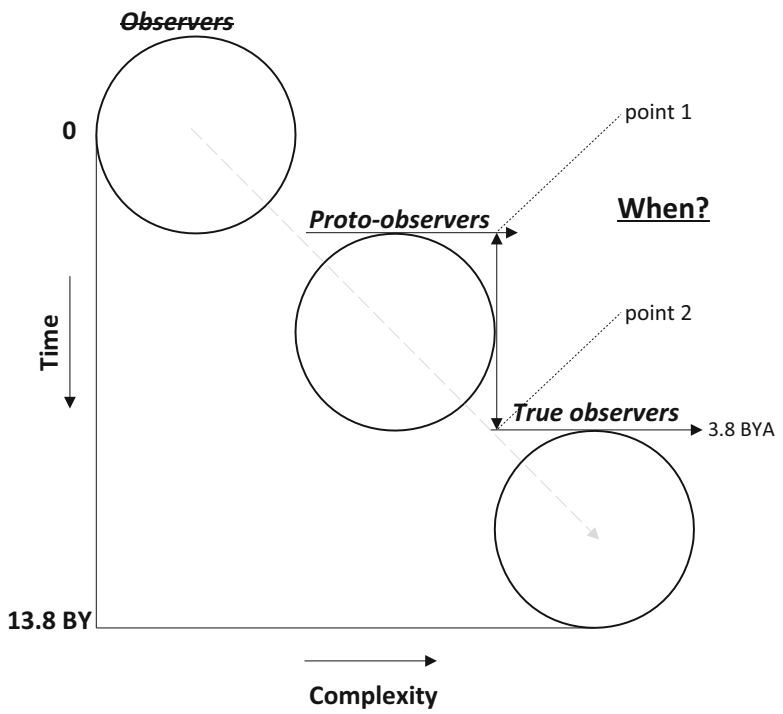

Fig. 4 The timeline of the emergence of organisms or true observers. The universe in its early stages lacks observers. A pre-requisite for the emergence of proto-observers and observers is the set of organic elements required for their function. As soon as the set of required elements is formed, this enables the emergence of proto-observers (point 1). Observers emerge (point 2) either very soon after the emergence of proto-observers (as in the case of (i) abiogenesis or (ii) tranpsermia; see text for details) or long after the emergence of protoobservers (as in the case of H-W thesis; see text for details). Drawing not to scale

follows that life, in the form of first fully functioning observers such as bacteria-like organisms, might have emerged early in the cosmic history at some first-generation Earth-like planet, following the emergence of the Earth-equivalents of the 'RNA world' and viruses as proto-observers. According to this view, the emergence of life on Earth is just a local cosmic event. As currently understood, the planet Earth was formed 4.5 BYA (billion years ago), leading soon after that to the emergence of the Earth-bound 'RNA world' and viruses as proto-observers, 4.1 BYA - 3.8 BYA, paving the way for the emergence of first living organisms or observers.

Another possibility consistent with the universe-wide abiogenesis process is the transpermia hypothesis. For example, life could have emerged through the process of abiogenesis on a planet like Mars, and then transferred to Earth through the rocky Mars ejecta containing microbes (Davies 2003). It is, therefore, possible that proto-observers such as viruses originated on Mars and then transferred to Earth. The timescale for the emergence of proto-observers, in this case, would be similar to the timescale applicable to the cosmic imperative thesis (Fig. 4).

However, the time-scale between points 1 and 2 (Fig. 4) can be dramatically longer. This possibility is consistent, at least in part, with a specific version of the panspermia hypothesis. The H-W thesis (Hoyle and Wickramasinghe 1981; Wickramasinghe et al. 2010; Wickramasinghe 2017) suggests that biogenic proto-observing forms, such as viruses, have the cometary origin. Once viruses emerge in comets, the entire cosmos may be seeded with these biogenic structures through the inter-galactic cometary traffic. Thus, the time-scale between points 1 and 2 (Fig. 4) may not depend on the processes such as planet formation. Viruses could have emerged very early in the cosmic history in the cometary bodies, as soon as the process of creation of organic 
elements was completed, in which case the time-scale between points 1 and 2 (Fig. 4) could be in the region of several billion years. In support of the H-W thesis, it has been argued recently that the retroviruses in the current form originated from the cosmos and coincided with the Cambrian explosion, thus representing the evolutionary driving force (Steele et al. 2018). Furthermore, it is well documented that the human genome is composite, containing DNA from a range of evolutionary ancestors (McFall-Ngai et al. 2013) including $45 \%$ of sequences that have the retroviral origin (Moelling and Broecker 2019).

\section{Q3}

Given that the answer to Q2a implies that all life forms are observers (Table 2), it is appropriate to use the term reference classes of observers. Every biological species becomes a reference class. The AP assumption is that the only reference class of observers capable of true observation is Homo sapiens. The concept of true observation has three elements: (i) the capacity to sense the cosmic scale information, (ii) the capacity to reflect on the sensory input and (iii) the capacity to send the signal of own existence deep into the cosmos and capture a potentially returning signal (communication). The proposed answer to Q3 is that, apart from Homo sapiens, additional reference classes of observers possess the capacity of true observation (Table 2). These include bacteria and the biosphere as a whole.

This answer may sound controversial or too speculative. However, it is neither less plausible, nor logically inferior to the current thinking behind SETI (see below). In the past, biologists including Ernst Mayr (cited in Lineweaver 2007), expressed deep doubts about the validity of the biological interpretation of SETI. Here is a sketch of the process of true observation which does not depend on the neural-type intelligence. Instead, it is entirely based on the bacterial cognition and interactions between bacteria as cognitive agents and proto-observing units such as viruses.

The first thing to note is that both bacteria and viruses exist as planetary-scale superorganisms - bacteriosphere and virosphere. Sonea and Mathieu (2001) characterized the bacteriosphere as "a world-wide-web of genetic information" that emerged as "a global bacterial superbiosystem" roughly 1 BY since the emergence of first bacteria on Earth. The bacteriosphere is still the most dominant form of life in the biosphere. A recent study suggests that bacteria are, by far, the most abundant life form in the biosphere, far more abundant than the other two domains of life Archaea and Eukarya (Hug et al. 2016). The fact that the most dominant form in the virosphere are phages, or bacterial viruses (Moelling and Broecker 2019), suggests that the bacteriosphere and the virosphere are structurally coupled.

The first SETI assumption is that intelligent observers must be capable of discovering electromagnetic signals and waves. The bacteriosphere "discovered" electromagnetic signals and waves when photosynthetic cyanobacteria emerged in the bacteriosphere. Cyanobacteria can sense the portion of the electromagnetic spectrum between $400 \mathrm{~nm}$ and $700 \mathrm{~nm}$ (visible light). Thus, the first criterion of the true observation is satisfied - the capacity to sense the cosmic-scale information in the form of bacterial discovery of electromagnetic signals and waves originating from the main star of our planetary system, the Sun (Fig. 5; i = "discovery" of electromagnetic waves). The second criterion, or the capacity to reflect on the sensory input, may be 
interpreted as the product of cyanobacterial sensing of the portion of electromagnetic spectrum combined with its metabolic habit to carry out photosynthesis, the final product of which is the oxygenation of the atmosphere (Fig. 5; ii=reflection on the sensory input). Thus, the reflection of the bacterisphere on the sensory input is in line with the biosemiotics concept of a sign reading, relational biology's modelling concept, natural learning as articulated by evolutionary epistemology and autopoiesis as the key process behind the systems view of life (Fig. 3; Table 1).

The third criterion within the SETI programme (active SETI), communication or the capacity to send the signal advertising own existence deep into the cosmos and to capture a potentially returning signal, is based on using radio-waves and radio-telescopes, or Van Neuman probes (Tipler 1981). In the case of bacteria, the man-made technology is entirely replaced by a natural technology - a form of biological tropism termed here cosmic tropism (Fig. 5; iii = communication). Biological tropism can be defined as the capacity of organisms to produce predictive models about their environments (Louie 2010). The cosmic tropism means that a cosmic scale biogenic structure, such as the bacteriosphere, is capable of producing the predictive model of its cosmic environment through advertising itself to the cosmos-wide flow of biogenic particles which may not necessarily be observers, such as viruses - the bacteriosphere is anticipating the virosphere (Fig. 5; iii). This possibility is conditional on accepting a version of the panspermia hypothesis: either the $\mathrm{H}-\mathrm{W}$ thesis or transpermia. The H-W thesis predicts that biogenic particles, including viruses and bacteria, are formed in the interior of comets and that there is a constant flow of biogenic particles from the

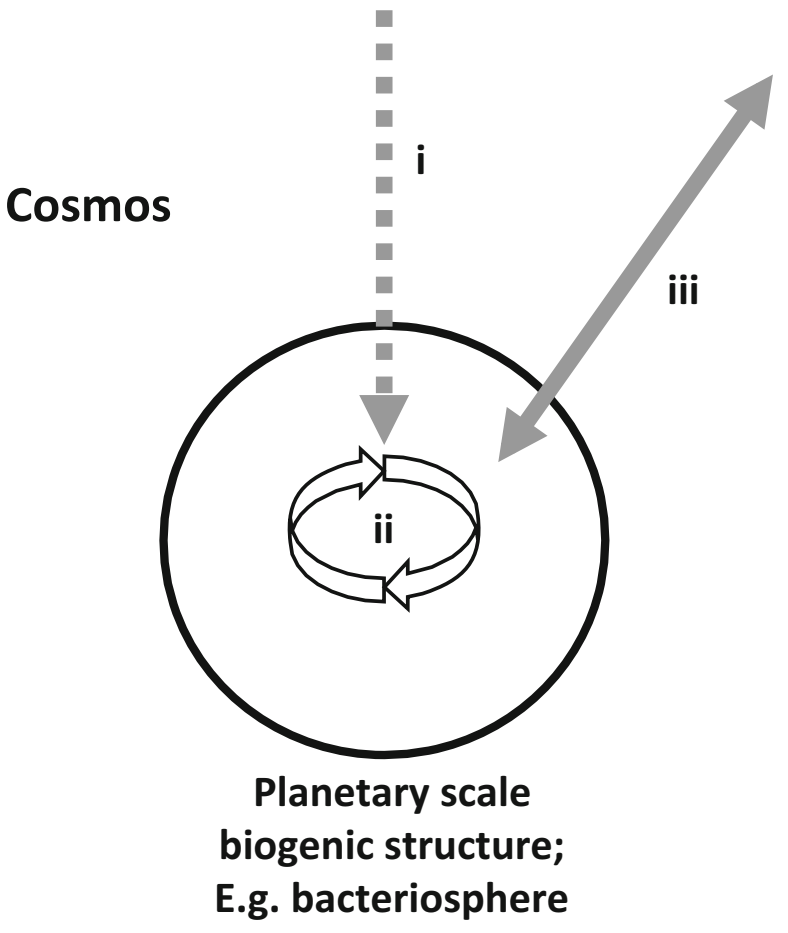

Fig. 5 The concept of true observers applied to the bacteriosphere. For the description of three elements, i-iii, required for the concept of true observation, see the text 
cosmos towards Earth (Hoyle and Wickramasinghe 1981; Wickramasinghe et al. 2010; Wickramasinghe 2017). Alternatively, the transpermia hypothesis combines the concept of abiogenesis occurring on Earth-like planets with the subsequent transport of microbes, such as viruses and bacteria, to neighbouring planets via rocky ejecta (Davies 2003). The H-W thesis and the transpermia hypothesis have been strongly defended (Sharov and Gordon 2013, 2017) at the expense of the SETI prediction that humantype observers must exist in the universe (Tipler 1981; Lineweaver 2007). Therefore, both the H-W thesis/transpermia hypothesis and the SETI programme should be treated equally until the evidence is available to support or reject one or both. By the same token the biosphere as a whole, may be regarded as the global biogenic structure that, through the process of cosmic tropism, may satisfy the criteria of the true observer (Fig. 5; iii).

\section{Q4}

The consequence of the relationship (structural coupling) between organisms as cognitive/semiotic agents and their environments, is the emergence of speciescentered worlds or Uexküll's Umwelten (Uexküll 2010), that form the basis of modern biosemiotics. Similarly, relational biology and the system's view of life interpret the organism-environment coupling as the capacity of organisms to project/anticipate their environments or "bring forth a world" (Table 1). In the context of Q4, it may be appropriate to call species-centered worlds "cognitive/semiotic universes" because organisms are cognitive/semiotic agents structurally coupled with their environments through species-specific sensoria.

The answer to Q4 is that all organisms (observers) possess species-specific observing worlds or collective cognitive/semiotic spaces, that may be called cognitive/ semiotic universes (Table 2). The cognitive/semiotic universe of a tick is as functional as the cognitive/semiotic universe of a human individual (Uexküll 2010). By following on Uexküll's lead, modern biosemiotics interprets the biosphere as a compendium of cognitive/semiotic universes, or the semiosphere (Hoffmeyer 1996), that we may call the cognitive/semiotic multiverse. Crossing the boundaries between individual universes is only possible through a form of biosemiotics known as the cross-kingdom communication (McFall-Ngai et al. 2013). This is apparent, for example, in the case of the communication between bacterial cells in our guts and our brain cells, known as the gut-brain axis (Bruce-Keller et al. 2018). Other examples of cross-kingdom communication are discussed elsewhere (Slijepcevic 2018).

Another feature all organisms (observers) share is that each cognitive/semiotic universe becomes a species-specific civilisation termed here biocivilisations (Table 2). Even though the term civilisation is usually applicable only to the human world, given that the structural coupling between organisms and environments leads to the emergence of natural artefacts including, for example (i) oxygenation of the atmosphere (cyanobacteria), (ii) food products through agriculture (ants and termites) (Mueller et al. 2005), (iii) animal settlements resembling human cities such as underground "cities" of Atta and Acromimex ants, or termite mounds in Africa and Australia (Wilson 2012), and (iv) huge biogenic structures such as multi-scale natural patterns known as Mima mounds (North America), murundus (Brazil) or heuweltjies (South Africa) (Tarnita et al. 2017), it is appropriate to consider these natural artefacts 
byproducts of biological technologies (Slijepcevic 2019c). As a result, the biosphere can be viewed as the global composite biocivilisation. It consists of individual biocivilisations that are structurally coupled to each other. This coupling is termed the interactome (Slijepcevic 2019a), the consequence of which is the biosphere homeostasis (Lovelock and Margulis 1974). (Definitions of cognitive/semiotic universes, the cognitive/semiotic multiverse, and biocivilisations, are given in Table 2).

\section{Discussion}

While the AP concept has been criticised as unscientific (Smolin 2004) or even arrogant (Barash 2018), it has solid support amongst astrophysicists (e.g. Livio and Rees 2005). The position towards AP taken in this study is that AP can be useful, primarily as a method for applying anthropic reasoning to eliminate anthropic bias. Evidence from different disciplines of biology (Fig. 3; Table1) indicates that the process of cognition is a biological universal. Brandon Carter suggested that the term Cognition Principle represents better what he meant when he was formulating AP (Carter 1983). Carter (1974) and others (Barrow and Tipler 1986) developed AP to understand the position of Homo sapiens relative to the rest of the universe. However, Carter (1983) and subsequent interpreters of AP (e.g. Bostrom 2002) did not appreciate enough evidence from biology, which I interpret in this study as a form of anthropic bias. If the capacity of cognition/semiosis/observation is a biological universal, several new elements should be added to the AP concept.

First, there are biogenic planetary structures with the cosmic-scale communicative potential that are usually ignored by mainstream science and philosophy. Such planetary structures are the bacteriosphere and virosphere (Sonea and Mathieu 2001; Moelling and Broecker 2019). These planetary-scale superbiosystems are best viewed as an invisible planetary cloud that goes to a certain depth into the planetary ground and to a certain height into the planetary atmosphere. The biogenic cloud has the potential to communicate with the biogenic particles coming from the cosmos as predicted by the $\mathrm{H}-\mathrm{W}$ thesis (Wickramasinghe et al. 2010) or transpermia hypothesis (Davies 2003). Thus, the communication reach of the biogenic cloud is truly a cosmic-scale reach, because there is no barrier for viruses coming from a different galaxy (H-W thesis), or a different planet (transpermia hypothesis), to make a 'contact' with the body of the Earth-bound bacteriosphere and virosphere. At the heart of this communication capacity is biological tropism which does not require consciousness of the human type, and yet it is based on the principles of cognition/semiosis. Importantly, the invisible microbial cloud of bacteria and viruses houses all other non-microbial life forms, or macrobes, such as plants and animals (Margulis 1993, 1999, 2004; Sonea and Mathieu 2001). This makes macrobes, including human beings, microbial or bacterial vectors. For example, the International Cosmic Station is already contaminated with bacteria from our microbiome (Checinska et al. 2015). Furthermore, our consciousness-based cognitive faculties and our technology, lag behind the bacterial counterpart in terms of the SETI potential (Fig. 5): the human communication window of temporal opportunity is dramatically smaller than that of the bacteriosphere.

Second, Homo sapiens as a macrobe from kingdom Animalia is a composite observer because every single cell in the human body has observing capacities in the sense 
outlined in section 4. Yet we take for granted the notion that we are biological singletons when it comes to interpreting the concept of observation, even though the ecological collective of our bodies houses trillions of cellular observers (Fig. 1). This discrepancy between the true individuality and the collective individuality challenges one of the explanatory concepts used to justify the AP style argumentation. The key conundrum of AP, known as the fine-tuning principle, according to which all physical constants of the universe are fine-tuned to the extent that a small change in parameters would mean that life, as we know it, would not emerge at all, is resolved through the concept of physical multiverse (Garriga and Vilenkin 2001; Koonin 2007; Tegmark 2009). According to the model of eternal inflation of the universe, all macroscopic events are repeatable an infinite number of times. Hence, there is not one universe but many universes or the multiverse. The physical multiverse concept is thought to be a scientific concept, meaning that it can be falsified (Tegmark 2009). On the other hand, some aspects of the concept may be too metaphysical to qualify as scientific (Ellis 2011).

However, evidence from biology points towards the existence of the cognitive/ semiotic multiverse. The human body is a cognitive/semiotic mini-multiverse: we are conglomerates of viruses, bacteria, archaea, protists, eukaryotic cells housing former bacteria (mitochondria) (McFall-Ngai et al. 2013), culminating in the emergence of the corporate body dominated by the neural-type intelligence and the consciousness (Slijepcevic 2018). Brain and nervous system, required for the rapid assessment of the changing organism-environment interactions that typify life for animals (Musall et al. 2019), combined with the consciousness, may give rise to a potentially misleading impression that we are true biological singletons, or absolute individuals (see Fig. 1) completely independent from the rest of the biosphere. The key question then becomes whether the concept of the physical multiverse is an illusion created by the human consciousness, given that the biosphere, containing us as an integrated component, is a complex web of cognitive/semiotic relationships that cannot be disentangled and "purified" to reflect cognitive/semiotic spaces of each species.

Carl Gustav Jung divided the human psyche into three areas: individual conscious (ego), individual unconscious and the collective unconscious (Jung 1980). He speculated that the collective unconscious is a biological continuum that can be traced to animals (Jung 1982). However, there is no reason to stop at animals because this violates the continuity thesis of the evolutionary process. Therefore, to bring Jung's thinking in line with the principles of evolution, the collective unconscious can be traced to first life forms, bacteria and archaea. In line with this possibility, recent research implicates the human microbiome as a natural force shaping development of the brain (Dinan et al. 2015), thus opening the route for empirical testing of the concept of collective unconscious all the way down to bacteria and archaea, as first observers on planet Earth from which all other observers descended (Margulis 2004). Here is an interesting question. Is our consciousness falsely projecting the existence of the physical multiverse as a result of the composite nature of our cognitive/observational faculties that (i) originated at the dawn of life with bacteria and archaea and (ii) reflect the entire cognitive/semiotic multiverse that developed in the last 3.8 BY? If the answer is positive, the AP concept requires deep changes.

Third, Barrow and Tipler (1986) argued that once an information processing entity emerges in the universe it will never be destroyed. This possibility named FAP, has been dismissed by some scientists (Gardner 1986). Others tend to interpret it as the emergence of 
post-biological evolution which may have a greater survival potential than human civilisation (Bostrom 2002). However, both views are ignorant of the planetary-scale information processing entities such as the bacteriosphere, and the biosphere as a whole (Slijepcevic 2019a). The bacterial planetary superorganism has been using the natural computation to regulate biogeochemical cycles of organic elements for billions of years (Sonea and Matheiu 2001), a possibility consistent with the informational view of life implicit in the concept of biological determinism (Davies 2003).

Margulis (1999) argued that bacteria are potentially an indestructible form of life. This possibility is supported by the fact that mass extinctions that occurred in the history of life several times have never been able to destroy bacteria. Bacteria have been existing in continuity for at least 3.8 BY, which is most of the existence of planet Earth and more than a quarter of the duration of the entire cosmos. Furthermore, a simple thought experiment supports the notion of bacterial indestructibility. Let us assume that humanity has a pressing need to destroy all bacteria on Earth. Theoretically, we can achieve this. We can use high doses of ionizing radiation, potent DNAdamaging chemicals and other agents capable of destroying life forms. However, this becomes an impossible task. If we attempt to eradicate bacteria from the biosphere we would need to destroy ourselves because we are bacterial vectors - all plants and animals, are carriers of species-specific bacteria-dominated microbiomes (Margulis 1993; Zilber-Rosenberg and Rosenberg 2008). Even if we imagine that an extraterrestrial civilisation can eradicate bacteria on Earth, this would mean the destruction of the entire biosphere, as the bacteriosphere represents its essential layer. Thus, Barrow and Tipler's FAP potentially exists in the form of the bacteriosphere, but it is wrongly named and interpreted. By contrast, the concept of biological determinism (Davies 2003) allows FAP through the informational context of life (Table 1).

In conclusion, natural intelligence may be viewed as a process equivalent to semiotic scaffolding, an important principle behind biosemiotics. Other disciplines, including relational biology, evolutionary epistemology and the systems view of life, interpret natural intelligence in a similar way to biosemiotics. Thus, the process of cognition/ semiosis - the essence of natural intelligence - is a biological universal. The novelties explicated in this study include the concepts of true observers, biocivilisations and the cognitive/semiotic multiverse.

Acknowledgements Supported by Brunel University London.

Open Access This article is licensed under a Creative Commons Attribution 4.0 International License, which permits use, sharing, adaptation, distribution and reproduction in any medium or format, as long as you give appropriate credit to the original author(s) and the source, provide a link to the Creative Commons licence, and indicate if changes were made. The images or other third party material in this article are included in the article's Creative Commons licence, unless indicated otherwise in a credit line to the material. If material is not included in the article's Creative Commons licence and your intended use is not permitted by statutory regulation or exceeds the permitted use, you will need to obtain permission directly from the copyright holder. To view a copy of this licence, visit http://creativecommons.org/licenses/by/4.0/.

\section{References}

Barash, D. P. (2018). Through a glass brightly: Using science to see our species as we really are. Oxford: Oxford University Press. 
Barbieri, M. (2009). A short history of biosemiotics. Biosemiotics, 2(2), 221-245.

Barrow, J. D., \& Tipler, F. J. (1996). The anthropic cosmological principle. Oxford: Oxford University Press. Bateson, G. (1979). Mind and nature: A necessary unity. New York: E P Dutton.

Beadle, G., \& Beadle, M. (1966). The language of life. Doubleday and Co: An introduction to the science of genetics. New York.

Ben-Jacob, E. (2009). Learning from Bacteria about natural information processing. Annals of the New York Academy of Sciences, 1178(1), 78-90.

Bertalanffy, L. (1968). General system theory. New York: Braziller.

Bostrom, N. (2014). Superintelligence: Paths, dangers, strategies. Oxford: Oxford University Press.

Bostrom, N. (2002). Anthropic bias: Observation selection effects in science and philosophy. New York: Routledge.

Bradie, M. (1986). Assessing evolutionary epistemology. Biology and Philosophy, 1(4), 401-459.

Bruce-Keller, A. J., Salbaum, J. M., \& Berthoud, H. (2018). Harnessing gut microbes for mental health: Getting from Here to there. Biological Psychiatry, 83(3), 214-223.

Campbell, D. T. (1960). Blind variation and selective retention in creative thought as in other knowledge processes. Psychological Review, 67(6), 380-400.

Campbell, D. T. (1974). Evolutionary epistemology. In P. A. Schlipp (Ed.), The philosophy of Karl popper (pp. 413-463). LaSalle, IL: Open Court.

Capra, F., \& Luisi, P. L. (2014). The systems view of life: A unifying vision. New York: Cambridge University Press.

Carter, B. (1974). Large number coincidences and the anthropic principle in cosmology. In: Longair MS (ed.) Confrontation of Cosmological Theories with Observational Data (pp. 291-298). International astronomical union / union Astronomique Internationale, vol 63. Dordrecht: Springer.

Carter, B. (1983). The anthropic principle and its implications for biological evolution. Philosophical Transactions of Royal Society A, 310(1512), 347-363.

Checinska, A., Probst, A. J., Vaishampayan, P., White, R. J., Kumar, D., Stepanov, et al. (2015). Microbiomes of the dust particles collected from the international Space Station and spacecraft assembly facilities. Microbiome, 3, 50. https://doi.org/10.1186/s40168-015-0116-3.

Ćirković, M. M., \& Vukotić, B. (2013). Astrobiological landscape: A platform for the neo-Copernican synthesis? International Journal of Astrobiology, 12(1), 87-93.

Crick, F. H. C., \& Orgel, L. E. (1973). Directed panspermia. Icarus, 19(3), 341-346.

Corning, P. A. (2007). Control information theory: The 'missing link' in the science of cybernetics. Systems Research and Behavioral Science, 24(3), 297-311.

Davies, P. C. W. (2003). How bio-friendly is the universe? International Journal of Astrobiology, 2(2), 115-120.

De Duve, C. (2011). Life as a cosmic imperative? Philosphical Transactions of the Royal Society A, 369(1936), 620-623.

Dinan, T. G., Stilling, R. M., Stanton, V., \& Cryan, J. F. (2015). Collective unconscious: How gut microbes shape human behaviour. Journal of Psychiatry Research, 63, 1-9. https://doi.org/10.1016/j.jpsychires.2015.02.021.

Drake, F. D. (1961). US Academy of Sciences conference on "extraterrestrial intelligent life". Green Bank: West Virginia.

Ellis, G. F. R. (2011). Does the multiverse really exists? Scientific American, 8, 38-43.

Erez, Z., Steinberger-Levy, I., Shamir, M., Doron, S., Stokar-Avihail, A., Peleg, Y., Melamed, S., Leavitt, A., Savidor, A., Albeck, S., Amitai, G., \& Sorek, R. (2017). Communication between viruses guides lysislysogeny decisions. Nature, 541(7638), 488-493.

Fleck, L. (1981). Genesis and development of a scientific fact. Chicago: The University of Chicago Press.

Gardner, M. (1986). WAP, SAP, PAP, and FAP. The New York Review of Books, 23(8), 22-25.

Garriga, J., \& Vilenkin, A. (2001). Many worlds in one. Physical Review D, 64, 43511.

Gontier, N. (2006). Introduction to evolutionary epistemology, language and culture. In N. Gontier, J. P. Bendegem, \& D. Aerts (Eds.), Evolutionary epistemology, language and culture (pp. 1-29). Netherlands: Springer.

Hoffmeyer, J. (2015). Introduction: Semiotic scaffolding. Biosemiotics, 8(2), 153-158.

Hoffmeyer, J. (1996). Signs of meaning in the universe. Indiana: Indiana University Press.

Hoyle, F., \& Wickramasinghe, N. C. (1981). Evolution from space. New York: Simon and Schuster.

Hug, L. A., Baker, B. J., Anantharaman, K., Brown, C. T., Probst, A. J., Castelle, C. J., Butterfield, C. N., Hernsdorf, A. W., Amano, Y., Ise, K., Suzuki, Y., Dudek, N., Relman, D. A., Finstad, K. M., Amundson, R., Thomas, B. C., \& Banfield, J. F. (2016). A new view of the tree of life. Nature Microbiology, 1(5), 16048.

Jablonka, E. (2002). Information: Its interpretation, its inheritance, and its sharing. Philosophy of Science, 69(4), 578-605).

Jones, E.M. (1985). "Where is everybody?" an account of Fermi's question. OSTI.GOV technical report, United States: Available at: https://www.osti.gov/servlets/purl/5746675 Accessed 17. November 2019.

Jung, C.G. (1980). Archetypes and the collective unconscious. The collected works of CG Jung, volume 9, part 1, translated by RFC Hull. Princeton; Princeton University press. 
Jung, C.G. (1982). Recent thoughts on schizophrenia. In The psychogenesis of mental disease. The collected works of CG Jung, volume 3, part 4, (written in English and published in the journal of mental science (London) 1939). Princeton: Princeton University press.

Kilstrup, M. (2015). Naturalizing semiotics: The triadic sign of Charles Sanders Peirce as a systems property. Progress in Biophysics and Molecular Biology, 119(3), 563-575.

Kineman, J. J. (2007). Modeling relations in nature and eco-informatics: A practical application of rosennean complexity. Chemistry and Biodiversity, 4(10), 2436-2457.

Kineman, J. (2011). Relational science: A synthesis. Axiomathes, 21(3), 393-437.

Koonin, E. V. (2007). The cosmological model of eternal inflation and the transition from chance to biological evolution in the history of life. Biology Direct, 2, 15.

Krampen, M. (1981). Phytosemiotics. Semiotica, 36, 3-4.

Kurzweil, R. (1990). The age of intelligent machines. Cambridge MA: MIT Press.

Lanza, R., \& Berman, B. (2009). Biocentrism: How life and consciousness are the keys to understanding the true nature of the universe. Dallas: BenBella.

Lineweaver, C. H. (2001). An estimate of the age distribution of terrestrial planets in the universe: Quantifying Metalicity as a selection effect. Icarus, 151(2), 307-313.

Lineweaver, C. H. (2007). Paleontological tests: Human-like intelligence is not a convergent feature of evolution. In J. Seckbach \& M. Walsh (Eds.), From Fossils to Astrobiology. Cellular Origin, Life in Extreme Habitats and Astrobiology (Vol. vol 12, pp. 353-368). Dordrecht: Springer.

Livio, M., \& Rees, M. J. (2005). Anthropic reasoning. Science, 309(5737), 1022-1023.

Louie, A. H., \& Kercel, S. W. (2007). Topology and life Redux: Robert Rosen's relational diagrams of living systems. Axiomathes, 17(2), 109-136.

Louie, A. H. (2010). Robert Rosen's anticipatory systems. Foresight, 12(3), 18-29.

Lovelock, J. E., \& Margulis, L. (1974). Atmospheric homeostasis by and for the biosphere: The Gaia hypothesis. Tellus, 26(1-2), 2-10.

Lyon, P. (2015). The cognitive cell: Bacterial behavior reconsidered. Frontiers in Microbiology, 6, 264.

Lyon, P. (2017). Environmental complexity, adaptability and bacterial cognition: Godfrey-Smith's hypothesis under the microscope. Biology and Philosophy, 32(3), 443-465.

Mandelbrot, B. B. (1983). The Fractal Geometry of Nature. InThe fractal geometry of nature. New York: Freeman.

Maor, I., Krauss, L., \& Starkman, G. (2008). Anthropic arguments and the cosmological constant, with and without the assumption of typicality. Physical Review Letters, 100(4), 041101.

McFall-Ngai, M., Hadfield, M. G., Bosch, T. C. G., Carey, H. V., Domazet-Lošo, T., Douglas, A. E., Dubilier, N., Eberl, G., Fukami, T., Gilbert, S. F., Hentschel, U., King, N., Kjelleberg, S., Knoll, A. H., Kremer, N., Mazmanian, S. K., Metcalf, J. L., Nealson, K., Pierce, N. E., Rawls, J. F., Reid, A., Ruby, E. G., Rumpho, M., Sanders, J. G., Tautz, D., \& Wernegreen, J. J. (2013). Animals in a bacterial world, a new imperative for the life sciences. Proceedings of National Academy of Sciences USA, 110(9), 3229-3236.

Margulis, L. (1993). Symbiosis in cell evolution (2nd ed.). New York: Freeman.

Margulis, L. (1999). The symbiotic planet: A new look at evolution. London: Phoenix.

Margulis, L. (2004). Serial endosymbiotic theory (SET) and composite individuality. Microbiology Today, 31(11), 172-174.

Maturana, H. R., \& Varela, F. J. (1980). Autopoiesis and cognition. Dordrecht: Reidel.

Moelling, K., \& Broecker, F. (2019). Viruses and evolution - viruses first? A personal perspective. Frontiers in Microbiology, 10, 523.

Mueller, U. G., Gerardo, N. M., Aanen, D. K., Six, D. L., \& Schultz, T. R. (2005). The evolution of agriculture in insects. Annual Review of Ecology, Evolution, and Systematics, 36(1), 563-595.

Musall, S., Kaufman, M. T., Juavinett, A. L., Gluf, S., \& Churchland, A. K. (2019). Single-trial neural dynamics are dominated by richly varied movements. Nature Neuroscience, 22, 1677-1686.

Nicolis, G., \& Prigogine, I. (1989). Exploring complexity. New York: WF Freeman \& Co Ltd..

Pattee, H. (2008). Physical and functional conditions for symbols, codes, and languages. Biosemiotics, 1(2), $147-168$.

Pattee, H.H. (1968). The physical basis of coding and reliability in biological evolution in Waddington C.H. (ed.) Toward a Theoretical Biology (1st ed.) (pp. 67-93). Edinburgh: Edinburgh University press.

Peirce, C. S. (1906). The basis of pragmaticism. In C. Hartshorne \& P. Weiss (Eds.), The collected papers of Charles Sanders Peirce, Vols I-VI (pp. 1931-1935). Cambridge MA: Harvard University Press.

Plotkin, H. C. (1987). Evolutionary epistemology as science. Biology and Philosophy, 2(3), 295-313.

Plotkin, H. C. (1982). Evolutionary epistemology and evolutionary theory. In H. C. Plotkin (Ed.), Learning, development and culture: Essays in evolutionary epistemology (pp. 3-16). Chichester: Wiley. 
Price, H. (2016). Now it's time to prepare for the Machinocene. https://aeon.co/ideas/now-it-s-time-to-preparefor-the-machinocene Accessed: $5^{\text {th }}$ November 2019.

Prodi, G. (1988). Material bases of signification. Semiotica, 69, 191-241.

Rosen, R. (1991). Life itself: A comprehensive inquiry into the nature, origin, and fabrication of life. New York: Columbia University Press.

Rosen, R. (1985). Anticipatory systems: Philosophical, mathematical, and methodological foundations. Oxford: Pergamon Press.

Saussure, F. (1916). Cours de linguistique générale. Paris: Payot.

Sebeok, T. A. (1972). Perspectives in zoosemiotics. The Hague: Mouton.

Shannon, C. E., \& Weaver, W. (1949). The mathematical theory of communication. Urbana: University of Illinois Press.

Sharov, A.A., \& Gordon, R. (2013). Life before earth. http://arxiv.org/abs/1304.3381. Accessed on $1^{\text {st }}$ June 2020.

Sharov, A.A., \& Gordon, R. (2017). Life before earth. In: Gordon, R. \& Sharov, a.a. (eds.) Habitability of the Universe before Earth (pp. 265-297); Elsevier B.V.: Amsterdam.

Shapiro, J. (2007). Bacteria are small but not stupid: Cognition, natural genetic engineering and sociobacteriology. Studies in History and Philosophy of Biological and Biomedical Sciences, 38, 807-819.

Slijepcevic, P. (2018). Evolutionary epistemology: Reviewing and reviving with new data the research programme for distributed biological intelligence. Biosystems, 163, 23-35.

Slijepcevic, P. (2019a). Principles of information processing and natural learning in biological systems. Journal for General Philosophy of Science. https://oi.org/10.1007/s10838-019-09471-9.

Slijepcevic, P. (2019b). Flora or Mona Lisa? Philosophy Now, August/September,18-19. https://philosophynow.org/issues/133/Flora_or_Mona_Lisa (Accessed: 10/11/2019).

Slijepcevic, P. (2019c). Anthropocene, Capitalocene, Machinocene: Illusions of instrumental reason. Philosophy and Society, 30(4), 543-570.

Smolin, L. (2004). Scientific alternatives to the anthropic principle. arXiv, hep-th/0407213.

Sonea, S. (1988). A bacterial way of life. Nature, 331(6153), 216.

Sonea, S. (1987). Bacterial viruses, prophages, and plasmids, reconsidered. Annals of New York Academy of Sciences, 503, 251-260.

Sonea, S., \& Panisset, M. (1983). A new bacteriology. Sudbury: Jones and Bartlett Publishers.

Sonea, S., \& Mathieu, L. G. (2001). Evolution of the genomic systems of prokaryotes and its momentous consequences. International Microbiology, 4, 67-71.

Steele, E,J., Steele, J.A., Al-Mufti, S., Augustyn, K.A., Chandrajith, R., Coghlan, J.P., et al. (2018). Cause of cambrian explosion - terrestrial or cosmic? Progress in Biophysics and Molecular Biology, 136, 3-23.

Tarnita, C. E., Bonachela, J. A., Sheffer, E., Guyton, J. A., Coverdale, T. C., Long, R. A., \& Pringle, R. M. (2017). A theoretical foundation for multi-scale regular vegetation patterns. Nature, 541(7637), 398-401.

Tegmark, M. (2009). The multiverse hierarchy. arXiv, 0905.1283.

Tipler, F. J. (1981). Extraterrestrial intelligent beings do not exist. Physics Today, 34(4), 9-71.

Trewavas, A. (2017). The foundations of plant intelligence. Interface focus, 7(3), 20160098.

Uexküll, J. (2010). A foray into the worlds of animals and humans. Mineapolis: University of Minnesota Press.

Vinge, V. (1993). The coming technological singularity: How to survive in the post-human era. Available at: http://ntrs.nasa.gov/search.jsp?R=19940022856 accessed 17 th $^{\text {November }} 2019$.

Wheeler, J. A. (1994). At home in the universe. Woodbury: American Institute of Physics.

Wickramasinghe, J., Wickramasinghe, N. C., \& Napier, B. (2010). Comets and the origin of life. Singapore: World Scientific.

Wickramasinghe, N. C. (2017). Proofs that life is cosmic. Singapore: World Scientific.

Wiener, N. (1948). Cybernetics. New York: Wiley.

Wilson, E. O. (2012). The social conquest of earth. New York: Liveright.

Zilber-Rosenberg, I., \& Rosenberg, E. (2008). Role of microorganisms in the evolution of animals and plants: The hologenome theory of evolution. FEMS Microbiology Review, 32(5), 723-735.

Publisher's Note Springer Nature remains neutral with regard to jurisdictional claims in published maps and institutional affiliations. 